DOI: https://doi.org/10.15688/lp.jvolsu.2019.1.11

UDC 364.4(470.45)

LBC 60.561.7(2P-4Вог)

\title{
INNOVATIVE TECHNOLOGIES IN SOCIAL WORK \\ IN THE VOLGOGRAD REGION \\ (THE REVIEW OF THE ROUNDTABLE DISCUSSION) ${ }^{1}$
}

\author{
Inna V. Vasilenko \\ Volgograd State University, Volgograd, Russian Federation \\ Natalia A. Skobelina \\ Volgograd State University, Volgograd, Russian Federation
}

УДК 364.4(470.45)

ББК 60.561.7(2Р-4Вог)

\section{ИННОВАЦИОННЫЕ ТЕХНОЛОГИИ \\ В СФЕРЕ СОЦИАЛЬНОГО ОБСЛУЖИВАНИЯ НАСЕЛЕНИЯ ВОЛГОГРАДСКОГО РЕГИОНА (ОБЗОР КРУГЛОГО СТОЛА) ${ }^{1}$}

\author{
Инна Викторовна Василенко \\ Волгоградский государственный университет, г. Волгоград, Российская Федерация \\ Наталья Анатольевна Скобелина \\ Волгоградский государственный университет, г. Волгоград, Российская Федерация
}

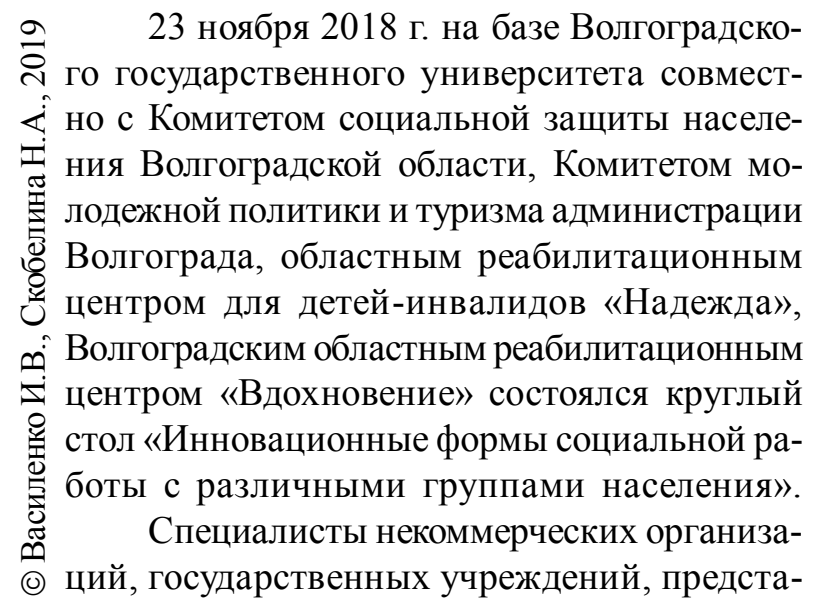

вители власти, ученые, практики и теоретики обменялись информацией об инновационных технологиях, способствующих повышению эффективности взаимодействия социальных работников с клиентами и учреждений социального обслуживания с различными группами населения. Участники круглого стола обозначили возможность применения инноваций в области социального обслуживания, определили новые технологии, которые используются в социальной работе с лицами с ограниченными возможностями здоровья и инвалидами. В теоретическом аспекте были 
представлены мультидисциплинарный и проектный подходы (Е.В. Казачкова, Н.А. Скобелина, Е.Г. Васильева, Н.А. Николенко, Я.И. Серова). Участники дискуссии представили как отечественные, так и зарубежные инновационные формы развития социальных практик (И.В. Василенко, А.Д. Аликов, Е.С. Онищенко, Л.В. Харинина, И.В. Радько).

Волгоградский областной реабилитационный центр «Вдохновение» имеет опыт внедрения телесно-ориентированного подхода в коррекцию проявлений психосоматических заболеваний у инвалидов и граждан пожилого возраста. Специалист по комплексной реабилитации центра «Вдохновение» Е.С. Онищенко представил технологию психофизической коррекции с элементами телесно-ориентированной терапии, которая включает беседы, лекции, демонстрацию мультимедийных материалов, показ упражнений, метод направленных визуализаций, комплекс упражнений адаптивной физической культуры. Последний включает, помимо упражнений, тренинг, направленный на развитие у людей с ограниченными возможностями здоровья самоощущений и самооценки своего физического и психического состояния и реакции на эти физические движения. Преимущества телесно-ориентированного подхода в том, что он действует быстрее и эффективнее большинства «вербальных» техник психологической коррекции. По его мнению, «этот подход сокращает время, необходимое для адаптации получателя услуг к условиям занятий и к специалистам».

Заведующий информационно-методическим отделением ГБСУ СО ОРЦДИ «Надежда» Е.В. Казачкова осветила в своем докладе технологии социального и психолого-педагогического сопровождения семей, воспитывающих ребенка-инвалида на базе областного реабилитационного центра, представила технологии дистанционного сопровождения семей. Специалист центра «Надежда» предложила модель междисциплинарного сопровождения ребенка, которая содержит три блока: диагностический, информационно-методический и межведомственный.

Педагог-психолог центра «Надежда» С.А. Карпова сообщила о технологиях, разработанных в рамках реализации междуна- родного проекта «Эразмус+» (визуальное расписание, коммуникационные устройства, дистанционная диагностика), которые повышают качество жизни детей с расстройствами аутического спектра, расширяющие его коммуникационные возможности. Особое внимание уделяется использованию компьютерных технологий для создания коммуникативной среды с целью развития навыков общения у детей-инвалидов. С.А. Карпова акцентировала внимание на обучении родителей технологиям эффективного взаимодействия с ребенком с расстройствами аутического спектра (технологии альтернативной коммуникации, методы визуальной поддержки, жетонирование, разработка единой стратегии сопровождения ребенка в учреждении и дома, организация родительского клуба, проведение мастерклассов). Специалистами центра применяется технология командного консультирования в работе с семьями, используется реабилитационное оборудование для работы с детьми (визуальное расписание, коммуникаторы, стабилотренажеры, аппаратная диагностика, интерактивные комплексы).

Профессор кафедры социологии ВолГУ И.В. Василенко в выступлении на тему «Арттехнологии как инновационные формы развития социальных практик в системе реабилитации детей-инвалидов» рассмотрела психологические и социальные аспекты применения данной технологии. В своем выступлении она отметила, что у этих технологий есть огромный неиспользованный потенциал, с помощью которого можно конструировать социальные практики и создавать условия для их понимания детьми-инвалидами. Музыка, литература, изобразительное искусство, танец, движение позволяют организовывать совокупность социальных действий, совершаемых индивидами, которые в определенных обстоятельствах ожидаются от индивида социумом. Далее И.В. Василенко выделила необходимые для развития арт-технологий условия: создание предметно-развивающей среды с учетом современных требований, включающих аудионоситель, бумагу для рисования, кисточки, тексты и т. д.; организация социальной среды соучастия детей-инвалидов, воспитателей, педагогов, специалистов в конкретных видах искусства, родителей, волонтеров; конструи- 
рование поля социальных практик внутри созданной социальной среды.

В теории социальной работы в настоящее время часто применяется междисциплинарный подход. Заведующий кафедрой социальных технологий ВолГУ Н.А. Скобелина в своем докладе «Научные и практические аспекты диагностики реабилитационного потенциала детей с ограниченными возможностями здоровья» рассмотрела процесс реабилитации детей с ОВ3, который включает в себя комплекс медицинских, психологических и педагогических мероприятий, разнообразных инновационных методик диагностирования. В длительный процесс реабилитации включается мультидисциплинарная бригада специалистов (психологи, педагоги, терапевты, физиотерапевты), которая занимается психодиагностическим обследованием, разработкой реабилитационного маршрута каждому клиенту, оценкой результативности реабилитационного процесса. Н.А. Скобелина отметила, что мультидисциплинарный подход позволяет всесторонне охарактеризовать процесс реабилитации, использовать показатели, с помощью которых на основе комплекса социальных, психологических, педагогических, медицинских факторов оцениваются возможности личности.

В Волгоградской области активно внедряются инновационные технологии в работе с различными категориями молодежи (И.В. Радько, О.А. Гоманенко, Е.Г. Шафоростов). По мнению ученых, внедрение в молодежную сферу уже имеющегося опыта в сфере обслуживания пожилых людей и инвалидов положительно скажется на рынке труда путем уменьшения безработного населения и заполнения кадрами тех специальностей, которые сейчас испытывают нехватку трудовых ресурсов (И.Н. Литвинова, Е.Г. Шафоростов).

Реализация проектного подхода в социальной сфере освящена в докладе доцента кафедры социологии ВолГУ Н.А. Николенко «Социальные проекты как способ реализации инновационного потенциала некоммерческих организаций на рынке социального обслуживания населения». В последние годы региональные некоммерческие организации активизировали свою деятельность в сфере оказания бесплатных и платных социальных ус- луг населению. В связи с этим следует отметить выступление доцента кафедры социологии ВолГУ Е.Г. Васильевой на тему «От социально ориентированных некоммерческих организаций к социальному предприятию: к вопросу об институциональных рамках и перспективах развития социального предпринимательства в современной России», в котором определена возможность включения некоммерческих организаций в сферу предпринимательства и выявлена роль некоммерческих организаций в развитии социального предпринимательства в Волгоградском регионе и в России в целом.

Таким образом, участники круглого стола и обменялись информацией о перспективных формах работы с различными категориями населения, особенно с лицами с ограниченными возможностями здоровья, и обозначили вектор инновационного развития социальной сферы Волгоградского региона. В ходе обсуждений были выделены пути совершенствования институциональных структур и развития социально ориентированных некоммерческих организаций, других видов социального предпринимательства, описаны современные физические, психологические, педагогические и социальные методики диагностики и реабилитации людей с ограниченными возможностями. Среди инновационных отмечались формы работы с привлечением родителей, волонтеров, различных категорий молодежи для создания благоприятной социальной среды для лиц с ограниченными возможностями здоровья.

\section{ПРИМЕЧАНИЕ}

${ }^{1}$ Обзор круглого стола подготовлен при поддержке гранта Российского фонда фундаментальных исследований (проект РФФИ № 18-413-342004) «Технологии СО НКО в условиях формирования доступной среды для лиц с ограниченными возможностями здоровья в Волгоградском регионе».

The review of the roundtable discussion is supported by the Russian Foundation for Basic Research grant (no. 18-413-342004 RFBR project) "Technologies of Socially Oriented Non-Profit Organizations in the Conditions of Forming an Accessible Environment for Disabled Persons in Volgograd Region." 
И.В. Василенко, Н.А. Скобелина. Инновационные технологии в сфере социального обслуживания населения

\section{Information about the Authors}

Inna V. Vasilenko, Doctor of Sciences (Philosophy), Professor, Department of Sociology, Volgograd State University, Prosp. Universitetsky, 100, 400062 Volgograd, Russian Federation, vasilenko@volsu.ru, https://orcid.org/0000-0002-9457-5889

Natalia A. Skobelina, Doctor of Sciences (Philosophy), Associate Professor, Professor, Department of Social Technologies, Volgograd State University, Prosp. Univtrsitetsky, 100, 400062 Volgograd, Russian Federation, volnatmax@volsu.ru, https://orcid.org/0000-0002-2108-187X

\section{Информация об авторах}

Инна Викторовна Василенко, доктор философских наук, профессор кафедры социологии, Волгоградский государственный университет, просп. Университетский, 100, 400062 г. Волгоград, Российская Федерация, vasilenko@volsu.ru, https://orcid.org/0000-0002-9457-5889

Наталья Анатольевна Скобелина, доктор социологических наук, доцент, профессор кафедры социальных технологий, Волгоградский государственный университет, просп. Университетский, 100, 400062 г. Волгоград, Российская Федерация, volnatmax@volsu.ru, https://orcid.org/ 0000-0002-2108-187X 